\title{
Effects of Cycling Temperatures on the Voltage Fade Phenomenon in $0.5 \mathrm{Li}_{2} \mathrm{MnO}_{3} \bullet 0.5 \mathrm{LiNi}_{0.375} \mathrm{Mn}_{0.375} \mathrm{Co}_{0.25} \mathrm{O}_{2}$ Cathodes
}

\author{
Anh Vu, Lee K. Walker, Javier Bareño, Anthony K. Burrell and Ira Bloom ${ }^{1}$ \\ Chemical Sciences and Engineering Division \\ Argonne National Laboratory \\ 9700 South Cass Avenue, Argonne, Illinois 60439
}

\begin{abstract}
The rate of voltage fade in $0.5 \mathrm{Li}_{2} \mathrm{MnO}_{3} \cdot 0.5 \mathrm{LiNi}_{0.375} \mathrm{Mn}_{0.375} \mathrm{Co}_{0.25} \mathrm{O}_{2}$ cathodes was measured in half-cells in a temperature range of 25 to $55^{\circ} \mathrm{C}$. On the basis of the dependence of the values of the open-circuit potential with cycle count and temperature, the voltage fade phenomenon seems to consist of two chemical processes: one that can be described using a parabolic rate law and another that uses a linear-with-time law. As the cycling temperature increased, the relative contributions of the two processes changed. On the basis of the overall rate versus temperature data, we believe the two processes may be in competition with one another.
\end{abstract}

Keywords: voltage fade, lithium ion battery, kinetics

${ }^{1}$ Corresponding author. E-mail: ira.bloom@anl.gov; +1 6302524516. 


\section{Introduction}

Lithium-manganese-rich nickel-manganese-cobalt oxide (LMR-NMC) cathode materials for lithium ion batteries have been attracting tremendous amounts of attention in recent years because of their higher capacity and lower cost compared with commercial $\mathrm{LiCoO}_{2}$ cathode materials. One issue with the LMR-NMC materials is that the voltage of the cell decreases continuously during cycling; this is commonly known as voltage fade [1,2]. This decrease in energy density may limit the usefulness of these materials in long-term, high-performance applications, such as transportation.

Several groups are exploring different methods to eliminate voltage fade by, for example, changing from a layered-layered to a layered-layered-spinel composite [3], changing crystal structure [4], doping [5], or using coatings [6]. Another possible approach is to control voltage fade kinetics, in hopes of slowing them down to the point where their effect would be minimal during the lifetime of the cell. As a first step toward this goal, we focus on the effect of cycling temperature in the rate of voltage fade in $0.5 \mathrm{Li}_{2} \mathrm{MnO}_{3} \cdot 0.5 \mathrm{LiNi}_{0.375} \mathrm{Mn}_{0.375} \mathrm{Co}_{0.25} \mathrm{O}_{2}$.

\section{Experimental}

Materials. The cathodes employed in this study were produced at the U.S. Department of Energy's (DOE's) Cell Analysis, Modeling, and Prototyping (CAMP) facility [7] at Argonne

National Laboratory (Argonne). Cathode laminates consisted of 86 percent by weight (wt $\%$ ) $0.5 \mathrm{Li}_{2} \mathrm{MnO}_{3} \bullet 0.5 \mathrm{LiNi}_{0.375} \mathrm{Mn}_{0.375} \mathrm{Co}_{0.25} \mathrm{O}_{2}$ powder (Toda Kogyo, Japan), 4 wt\% SFG-6 (a 
conductive additive), $2 \mathrm{wt} \%$ Super-P (also a conductive additive), and $8 \mathrm{wt} \%$ Solvey 5130 binder. This slurry was coated on aluminum foil that was about $15 \mu \mathrm{m}$ thick. The calendared electrode thickness was $94 \mu \mathrm{m}$, and the cathode loading was $14 \mathrm{mg} \mathrm{cm}^{-2}$. Portions of the laminates were assembled into coin cells (Hohsen, size 2032) in an argon-filled glove box. The electrolyte consisted of a 1.2-M LiPF 6 solution in ethylene carbonate-ethylmethyl carbonate (3:7 by weight). The negative electrode was lithium foil.

Electrochemical Tests. All electrochemical tests were carried out using custom battery test equipment based on National Instruments hardware and LabView® software. Galvanostatic charge-discharge measurements were performed using Argonne's voltage fade protocol [6, 8], in which the cells are charged and discharged at $10 \mathrm{~mA} \mathrm{~g}^{-1}$ in the first cycle and $20 \mathrm{~mA} \mathrm{~g}^{-1}$ in following cycles. The voltage limits for the cycling were 4.7 and $2.0 \mathrm{~V}$ for charge and discharge, respectively. The cell distribution and cycling temperatures are listed in Table 1 . The initial charge (activation) and discharge subcycles were defined as Charge 0 and Discharge0, respectively (see Fig. 1).

Ten-minute current interrupts were used in all subcycles after Discharge0. In the charge subcycles, they were at $3.5,3.9$, and $4.3 \mathrm{~V}$; in the discharge subcycle, they were at 4.0, 3.6, and 3.2 V. The values of the open-circuit potential $(\mathrm{OCV})$ were taken from the last point during these current-interrupt periods.

Data reduction. The current-interrupt data were extracted from the cycling data, as described above. Because it had current-interrupt information, the discharge subcycle after Discharge0 
was used as the $t=0$ reference point for data reduction. The FORECAST function in Microsoft ${ }^{\circledR}$ Excel ${ }^{\circledR}$ was used to estimate the values of the OCV at $50 \%$ state of charge (SOC) using the measured values as input. For each test temperature, the estimates were averaged. The decrease in voltage was then calculated as the difference of the OCV at time $t=0$ and $t=t_{\mathrm{i}}$. Curve-fitting was performed on each set of differences using the LINEST function in Excel®. The data were fit to two equations, one based on power-law kinetics (Eq. 1) and another based on a mixture of parabolic and linear kinetics (Eq. 2):

$$
\begin{gathered}
\mathrm{Y}=a t^{\mathrm{n}} \\
\mathrm{Y}=a t^{1 / 2}+b t, \quad \text { Eq. } 1 \\
\end{gathered}
$$

where $\mathrm{Y}$ is the parameter of interest, $t$ is cycle count, and $a, b$, and $n$ are fitting constants. Eq. 1 was linearized by taking the natural logarithm of both sides of the equation to facilitate curve fitting. Thus, Eq. 1 was transformed into Eq. 3:

$$
\ln (\mathrm{Y})=a+n \ln (t) . \quad \text { Eq. } 3
$$

\section{Results}

As each cell was cycled, the plot of cell voltage versus capacity indicated that there were changes in the shape of this curve. Plotting the voltage data against normalized capacity was used to highlight these changes, such as those shown in Fig. 1. By examining Fig.1, one can see 
that the current interrupt measurements occurred at approximately 80,50 , and $20 \%$ SOC, where $\% \mathrm{SOC}=100 *(1$-normalized capacity), in the initial discharge curve after Discharge0. Further, examining the amount of change in voltage at these fixed SOC points showed that the OCV variation with cycle count was larger at about $50 \%$ SOC than at $80 \%$ SOC-allowing for a better determination of the degree of voltage fade — and was more likely to be a better indicator than those values at $20 \%$ SOC. The average of these voltage values per cycle from the cells cycled at a given temperature are plotted in Fig. 2; they decrease with cycling.

Fig. 3 shows a plot of the values of OCV at 50\% SOC from discharge cycle 1 as a function of cycling temperature. As expected, the value of OCV decreases with increases in cycling temperature, consistent with Nernstian-like behavior [10].

A plot of the voltage differences against cycle count is shown in Fig. 4, as markers. Fitting these data, one dataset at a time, to Eq. 1 (via Eq. 3) yields the fitting parameters and regression coefficients listed in Table 2. (To avoid redundancy, the plot of the fits using Eq. 1 are not shown. The shapes of the fitted curves are only slightly different when using Eq. 1 from those seen when using Eq. 2.) Based on the values of the regression coefficients in Table 2, the fits were very good. The values of $n$-the power of time (that is, cycle count) - in Table 2 are between those expected for simple parabolic kinetics, 0.5 , and for linear-with-time, 1 . Thus, the values of $n$ indicate that a mixture of the two mechanisms may be present.

The literature contains examples of processes that are a combination of linear and parabolic kinetics [10-16]. These processes were termed "paralinear" and were found to occur in the 
oxidation or sulfiding of metals when there was a change in scale morphology or when a volatile species was involved. This type of kinetic law is used when the initial barrier scale ceases to be rate-limiting because of a change in morphology or loss of a product species.

Applying the idea of two mechanisms instead of one, the data in Fig. 4 were fit to Eq. 2, another two-parameter fit. These results are also shown in Fig. 4, as solid curves, and in Table 3. Again, from the values of the regression coefficients, the fits were excellent.

An examination of the values of $a$ and $b$ in Table 3 shows that temperature-based trends exist. The values of $a$, the coefficient of the parabolic term, decrease with increasing temperature, while the values of $b$ increase with temperature. At about $55^{\circ} \mathrm{C}$, the rates of the two processes are about equal. The trends in the data are shown in Fig. 5. Performing least-squares regression on these data shows that both display strong linear tendencies; the values of $r^{2}$ were 0.99 and 0.92 , respectively, for datasets $a$ and $b$.

\section{Discussion}

The values of the OCV are proportional to the ratio of lithium activities in the cathode material and lithium metal. Therefore, the voltage fade phenomenon can be viewed as a process that changes the activity ratio, and the observed OCV can be used as a probe to monitor this process.

The data in Fig. 5 show that the voltage fade process seems to consist of two reaction mechanisms - one that is proportional to $t^{1 / 2}$ and one that is linear with time - and that the 
parabolic mechanism is usually faster than the linear-with-time mechanism. Parabolic mechanisms $\left(t^{1 / 2}\right)$ usually have strong diffusion dependence and tend to be thermally activated. In the case of the voltage fade process, the presence of a parabolic mechanism implies that the rate-limiting step depends on diffusion in the solid state to the reaction site. Linear-with-time mechanisms $(t)$ arise when there is no transport limit in the reaction. This may be the case when there is a large excess of one reactant and access to the reaction site is unhindered. In this case, only the rate of reaction would be seen.

Given simple chemical principles, one would expect the rate of both parabolic and linear-withtime processes to increase with temperature. However, that is not what Fig. 5 shows. Instead, only the apparent rate of the linear-with-time process increases with time; the apparent rate of the parabolic process decreases.

It is possible to solve this apparent paradox by hypothesizing that two different, competing mechanisms are in operation. For example, the parabolic mechanism could arise from a slow transformation of the delithiated LMR-NMC (with, in this case, a metal-to-oxygen ratio, M:O, = $0.4)$ to a spinel $(\mathrm{M}: \mathrm{O}$ ratio $=0.5)$, which creates excess oxygen that needs to diffuse out of the crystal structure. The diffusion of oxygen out of the structure can be expected to be slow, resulting in diffusion-limited, parabolic kinetics. Contrary to the observation in Fig. 5, in this scenario, the reaction should proceed faster (that is, parameter $a$ should increase) as the diffusion rate of oxygen increases at higher temperatures. 
The apparent decreasing rate of diffusion with increasing temperature (decreasing parameter $a$ ) could be caused by the increase in a competing mechanism ( $b$ parameter), which reduces the availability of the shared reactant, delithiated LMR-NMC, for the parabolic process. One candidate for such reaction is the migration of TM (and possibly Li) atoms into stable, dumbbell defects in the unperturbed oxygen structure [2,17 and refs. therein]. As the migrating cations stabilize the excess oxygen in the structure, no oxygen needs to diffuse, consistent with the linear dependence of the $b$ parameter with temperature. In order to proceed spontaneously, the creation of dumbbell structures needs to be exothermic, which would imply that the $b$-parameter should decrease with temperature. However, if this process were kinetically limited —as is expected for the slow movement of transition metals through the triangular faces of the $\mathrm{MO}_{6}$ octahedra-it could proceed faster at higher temperatures ( $b$ parameter should increase, as observed) because more thermal energy is available to overcome the activation barrier. The competition between long-range diffusion of excess oxygen resulting from a transformation to spinel and kineticallylimited, short-range reorganization of cations stabilizing the excess oxygen would result in expected kinetic rates consistent with our experimental observations.

\section{Conclusion}

The rate of voltage fade in $0.5 \mathrm{Li}_{2} \mathrm{MnO}_{3} \bullet 0.5 \mathrm{LiNi}_{0.375} \mathrm{Mn}_{0.375} \mathrm{Co}_{0.25} \mathrm{O}_{2}$ cathodes was measured in half-cells in the temperature range of 25 to $55^{\circ} \mathrm{C}$. Changes in the values of the open-circuit potential at $50 \%$ SOC were used to monitor this process. On the basis of the dependence of the values at $\mathrm{OCV}$, the voltage fade phenomenon seems to consist of two chemical processes: one that can be described using a parabolic rate law and another that uses a linear-with-time law. As 
the cycling temperature increased, the relative contributions of the two processes changed; the parabolic process decreased and the linear-with-time process increased. At about $55^{\circ} \mathrm{C}$, the rates of the two processes were about equal. On the basis of the change in contribution to the overall rate versus temperature data, we believe the two processes may be in competition with one another.

\section{Acknowledgment}

The authors gratefully acknowledge the donation of cathode laminates from the CAMP facility at Argonne. The CAMP facility is fully supported by the DOE Vehicle Technologies Program within the core funding of the Applied Battery Research (ABR) for Transportation Program. This work was performed under the auspices of the DOE Office of Vehicle Technologies, Hybrid and Electric Systems, under Contract No. DE-AC02-06CH11357. The submitted manuscript has been created by UChicago Argonne, LLC, Operator of Argonne National Laboratory ("Argonne"). Argonne, a U.S. Department of Energy Office of Science laboratory, is operated under Contract No. DE-AC02-06CH11357. The U.S. Government retains for itself, and others acting on its behalf, a paid-up nonexclusive, irrevocable worldwide license in said article to reproduce, prepare derivative works, distribute copies to the public, and perform publicly and display publicly, by or on behalf of the Government. 


\section{References}

1. J. R. Croy, D. Kim, M. Balasubramanian, K. Gallagher, S.-H. Kang, M. M. Thackeray, J. Electrochem. Soc., 159 (2012), A781-A790.

2. K. G. Gallagher, J. R. Croy, M. Balasubramanian, M. Bettge, D. P. Abraham, A. Burrell, M. M. Thackeray, Electrochemistry Communications, 33 (2013), 96-98.

3. D. Kim, G. Sandi, J. R. Croy, K. G. Gallagher, S.-H. Kang, E. Lee, M. D. Slater, C. S. Johnson, M. M. Thackeray, J. Electrochem. Soc., 160, (2013), A21-A38.

4. N. K. Karan, M. D. Slater, F. Dogan, D. Kim, C. S. Johnson, M. Balasubramanian, J. Electrochem. Soc., 161, (2014), A1107-A1115.

5. E. Lee, R. Koritala, D. J. Miller, C. S. Johnson, J. Electrochem. Soc. (2014), in press.

6. I. Bloom, L. Trahey, A. Abouimrane, I. Belharouak, X. Zhang, Q. Wu, W. Lu, D. P. Abraham, M. Bettge, J. W. Elam, X. Meng, A. K. Burrell, C. Ban, R. Tenent, J. Nanda N. Dudney, J. Power Sources, 249 (2014), 509-514.

7. S.E. Trask, Y. Li, J.J. Kubal, M. Bettge, B.J. Polzin, Y. Zhu, A.N. Jansen, D.P. Abraham. J. Power Sources, $\underline{259}$ (2014), 233-244.

8. M. Bettge, Y. Li, K. Gallagher, Y. Zhu, Q. Wu, W. Lu, I. Bloom, D. P. Abraham, J. Electrochem. Soc., 160 (2013), A2046-A2055.

9. A. J. Bard and L. R. Faulkner, Electrochemical Methods: Fundamentals and Applications, John Wiley \& Sons, 1980.

10. E. W. Haycock, J. Electrochem. Soc., 106 (1959), 764-771.

11. E. W. Haycock, J. Electrochem. Soc., 106 (1959), 771-775. 
12. D. Wajszel, J. Electrochem. Soc., 110 (1963), 504-507.

13. J. G. Schnizlein, D. F. Fischer, J. Electrochem. Soc., 114 (1967), 23-29.

14. C. S. Tedmon, J. Electrochem. Soc., $\underline{113}$ (1966), 766-768.

15. D. S. Fox, E. J. Opila, Q.G. N. Nguyen, D. L. Humphrey, S. M. Lewton, J. Am. Ceram. Soc., $\underline{86}$ (2003), 1256-1261.

16. B. Pujilaksono, T. Jonsson, M. Halvarsson, I. Panas, J.-E. Svensson, L.-G. Johansson, Oxid. Met., 70 (2008), 163-188.

17. J. R. Croy, K. G. Gallagher, M. Balasubramanian, Z. Chen, Y. Ren, D. Kim, S.-H. Kang, D. W. Dees, M. M. Thackery, J. Phys. Chem C, 117 (2013), 6525-6536. 
Table 1. Cell distribution used in this study.

$$
\text { Cycling }
$$

temperature, ${ }^{\circ} \mathrm{C} \quad$ Cell count

\begin{tabular}{ll}
25 & 4 \\
35 & 3 \\
45 & 3 \\
55 & 5 \\
\hline
\end{tabular}

Table 2. Values of fitting constants and regression coefficients using Eq. 1

\begin{tabular}{cccc}
\hline Temperature, ${ }^{\circ} \mathrm{C}$ & $\ln (a)(\text { s.e })^{*}$ & $n$ (s.e. $)$ & $r^{2}$ \\
\hline 25 & $-4.032\left(2.00 \times 10^{-2}\right)$ & $6.39 \times 10^{-1}\left(9.00 \times 10^{-3}\right)$ & $>0.99$ \\
35 & $-4.135\left(3.40 \times 10^{-2}\right)$ & $7.62 \times 10^{-1}\left(1.70 \times 10^{-3}\right)$ & $>0.99$ \\
45 & $-4.126\left(4.30 \times 10^{-2}\right)$ & $7.71 \times 10^{-1}\left(2.00 \times 10^{-3}\right)$ & 0.99 \\
55 & $-4.006\left(1.50 \times 10^{-2}\right)$ & $8.60 \times 10^{-1}\left(8.00 \times 10^{-3}\right)$ & $>0.99$ \\
\hline
\end{tabular}

s.e. $=$ standard error

Table 3. Fitting constants and regression coefficients from the least-squares regression of the data in Fig. 4 to Eq. 2.

\begin{tabular}{cccc}
\hline $\begin{array}{c}\text { Cycling } \\
\text { temperature, }{ }^{\circ} \mathrm{C}\end{array}$ & $\begin{array}{c}a(\text { s.e. }), \\
\text { Vcycles }^{-1 / 2}\end{array}$ & $\begin{array}{c}b \text { (s.e. }), \\
\text { Vcycles }^{-1}\end{array}$ & $r^{2}$ \\
\hline 25 & $1.87 \times 10^{-2}$ & $1.77 \times 10^{-3}$ & $>0.99$ \\
& $\left(8.60 \times 10^{-4}\right)$ & $\left(2.45 \times 10^{-4}\right)$ & \\
35 & $1.60 \times 10^{-2}$ & $4.06 \times 10^{-3}$ & $>0.99$ \\
& $\left(1.84 \times 10^{-4}\right)$ & $\left(5.74 \times 10^{-4}\right)$ & \\
45 & $1.40 \times 10^{-2}$ & $5.09 \times 10^{-3}$ & $>0.99$ \\
& $\left(1.54 \times 10^{-4}\right)$ & $\left(4.65 \times 10^{-4}\right)$ & \\
55 & $1.06 \times 10^{-2}$ & $9.79 \times 10^{-3}$ & $>0.99$ \\
& $\left(1.07 \times 10^{-4}\right)$ & $\left(3.55 \times 10^{-4}\right)$ & \\
\hline
\end{tabular}




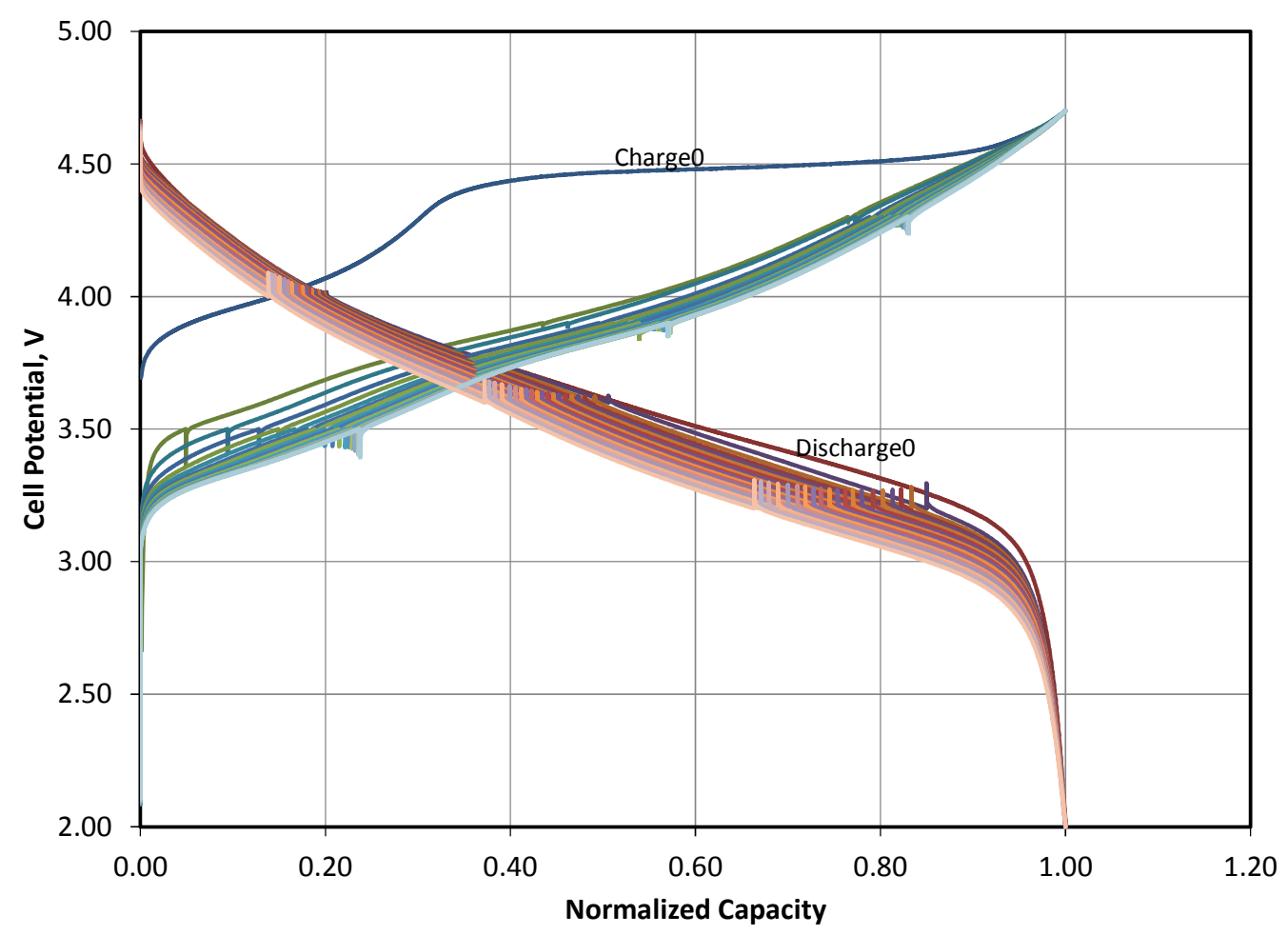

Fig. 1. Cell potential vs. normalized capacity from a cell cycled at $25^{\circ} \mathrm{C}$. The activation cycle is labeled Charge0 and the subsequent discharge is labeled Discharge0. The upward and downward tick marks on each curve after Discharge 0 are from the current interrupt measurements. Cycle count increases in the downward direction. 


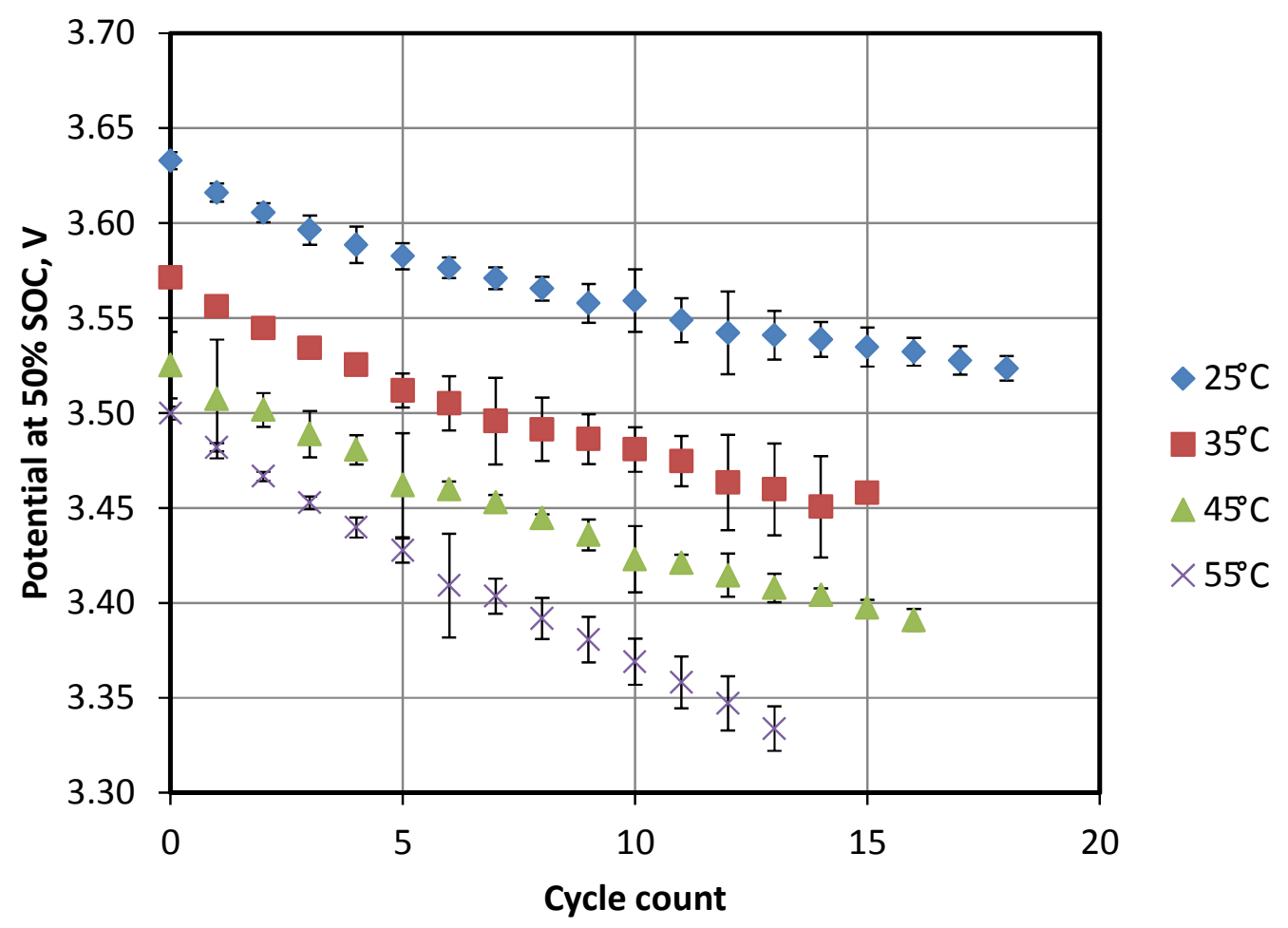

Fig. 2. OCV at 50\% SOC vs. cycle count and temperature. Each marker represents an average of OCV values from the cells cycled at that temperature. Error bars $( \pm 2 \sigma)$ around each data point are also shown. 


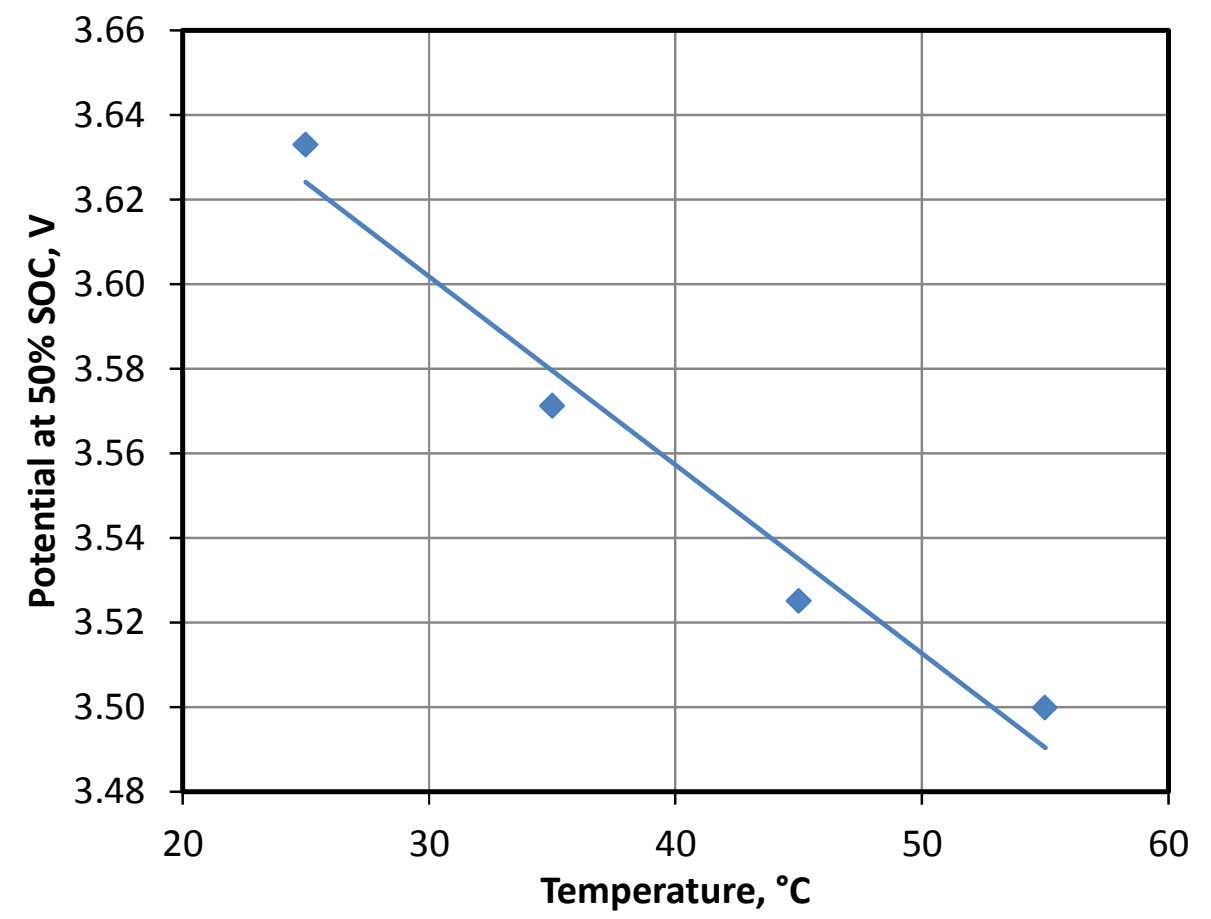

Fig. 3. Open circuit potential from discharge cycle 1 at $50 \%$ SOC vs. cycling temperature. The experimental data are given as markers and the least-squares-fit line as a solid curve. The error around each data point $( \pm 2 \sigma)$ was on the order of $4 \mathrm{mV}$. The value of the regression coefficient, $r^{2}$, was 0.97 , indicating that the fit was good. The slope of the least-squares-fit line was $-4.45(0.58) \mathrm{mV} / \mathrm{K}$. 


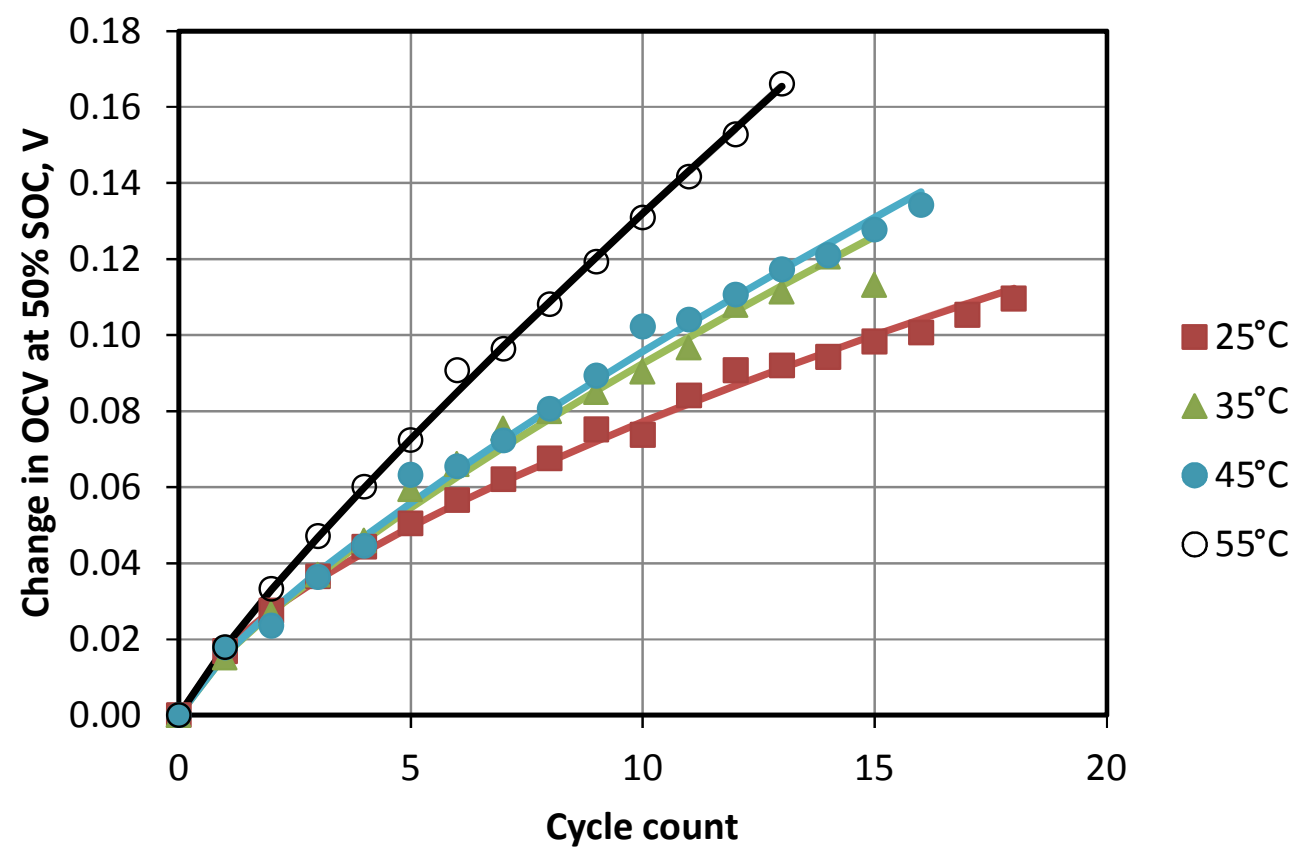

Fig. 4. Difference in OCV at 50\% SOC vs. cycle count and temperature. The data points are given as markers and the least-squares results, using Eq. 2, as solid curves. The numbers in the legend represent the cycling temperature in ${ }^{\circ} \mathrm{C}$.

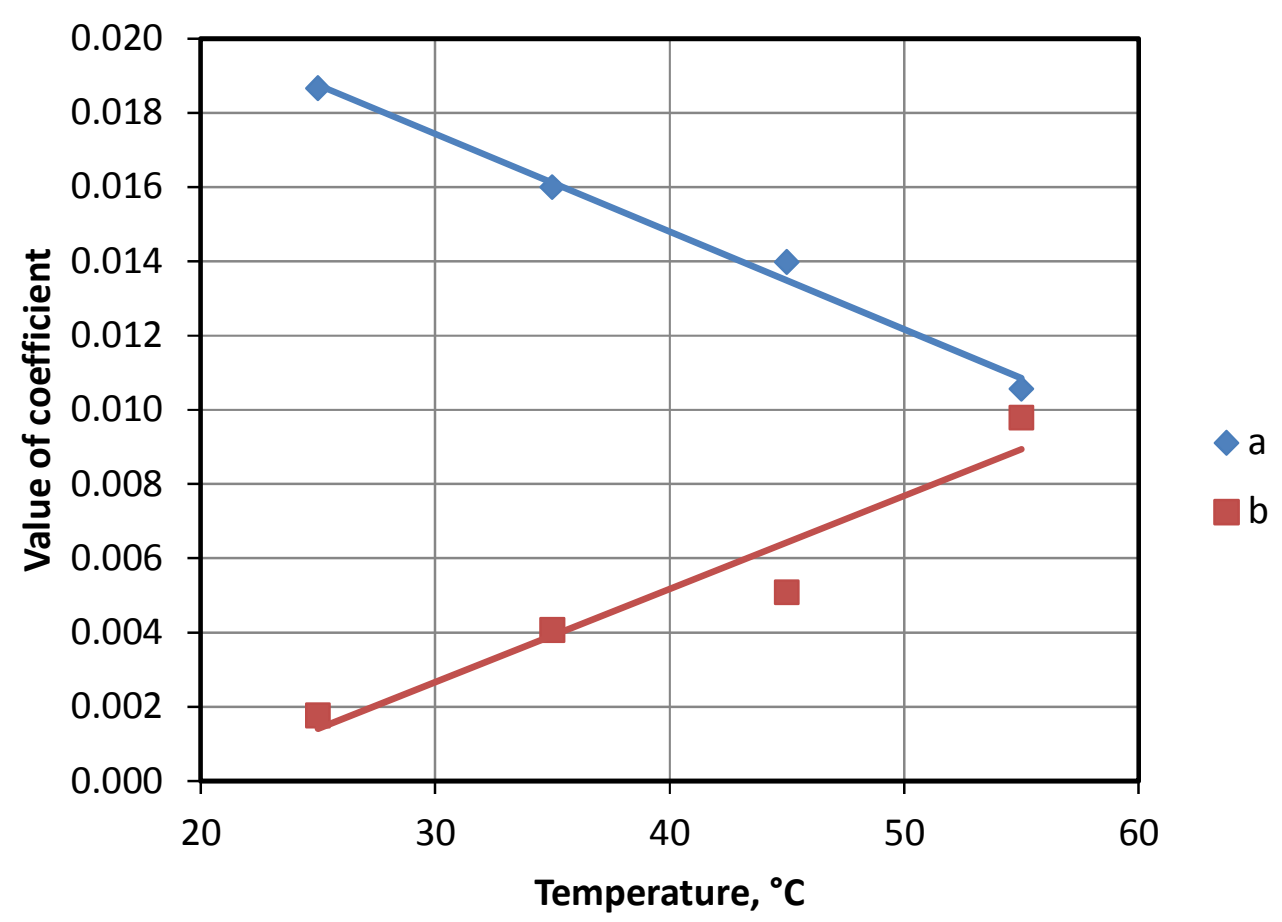

Fig. 5. Values of the coefficients, $a$ and $b$, vs. temperature. The markers represent the values of the contributions and the solid curves, the least-squares fit. The contributions of the parabolic $(a)$ and linear $(b)$ terms vary with temperature. 